J. Amer. Soc. Hort. Sci. 115(1):165-169. 1990.

\title{
Selection for Betalain Pigment Concentrations and Total Dissolved Solids in Red Table Beets
}

\author{
D.J. Wolyn' and W.H. Gabelman \\ Department of Horticulture, University of Wisconsin, Madison, WI 53706 \\ Additional index words. Beta vulgaris, betacyanin, betaxanthine, selection index
}

\begin{abstract}
Three cycles of half-sib family selection were practiced in a previously unselected table beet (Beta vulgaris L.) population to produce high pigment-high solids (HPHS) and high pigment-low solids (HPLS) populations. A selection index (total pigment concentration/percent dissolved solids) was used to improve the HPLS population and another selection index (total pigment concentration $\times$ percent dissolved solids) was used to improve the HPHS population. Rates of gain for total pigment were $22.2 \%$ per cycle in the HPHS population and $18.4 \%$ per cycle in the HPLS population. The HPHS and HPLS populations showed directional but nonsignificant changes for dissolved solids: $3.0 \%$ and $-\mathbf{2 . 6 \%}$ per cycle, respectively. The rate of gain per cycle for selection index value $(29.1 \%)$ was greater in the HPHS population than in the HPLS population $(21.2 \%)$. Realized heritabilities were high for total pigment $(0.81$ and 0.82$)$ and selection index $(0.74$ and 0.74$)$ and low for dissolved solids $(0.25$ and 0.27$)$ in both populations. Variation among families was greater for total pigment than for dissolved solids.
\end{abstract}

The banning of some synthetic red food colorants because of possible carcinogenic effects has renewed interest in natural sources of red pigment. Table beet pigments, violet betacyanins (BC), and yellow betaxanthines (BX), which, in combination, produce a red hue, can be used in certain foods (Pasch et al., 1975; von Elbe et al., 1974). However, beet juice concentrates and powders presently available contain pigment concentrations of $1 \%$ or less, precluding their widespread use (Riboh, 1977). Solutes, mostly sugars, present in beet extracts hinder the pro-

Received for publication 17 Jan. 1989. Research supported by Color-Treme Co., Clyman, Wis., a Division of Beatrice Food Co., and by the College of Agricultural and Life Sciences, Univ. of Wisconsin, Madison. This investigation is a portion of a thesis presented in partial fulfillment of the requirements for the $\mathrm{PhD}$ degree. The cost of publishing this paper was defrayed in part by the payment of page charges. Under postal regulations, this paper therefore must be hereby marked advertisement solely to indicate this fact.

'Present address: Dept. of Horticultural Science, Univ. of Guelph, Guelph, Ont. N1G 2W1, Canada. duction of highly concentrated solutions (von Elbe, 1978), necessitating the use of large volumes of extract to achieve a desired color intensity. Specific pigment hues of beet extracts, determined by the $\mathrm{BC}: \mathrm{BX}$ ratio, are required for the coloring of different food items. Cultivars with high pigment and low dissolved solids concentrations would provide a source of enhanced pigment concentrations in beet extracts used by the food industry.

Successful selection for concentrations of pigment and dissolved solids depends on the availability of adequate genetic variability for both traits and a favorable genetic correlation between traits. Genetic variation among cultivars for pigment concentration has been indicated $(\mathrm{Ng}$ and Lee, 1978; Nilsson, 1973; von Elbe et al., 1972; Watson and Gabelman, 1982). Three- and four-fold ranges of pigment concentrations have been reported for BX (von Elbe et al., 1972) and BC ( $\mathrm{Ng}$ and Lee, 1978), respectively. Variation for sugar content in beet has contributed to a $100 \%$ increase of this trait through breeding (Coons, 
1936). Highly significant general and specific combining ability estimates for concentrations of $\mathrm{BC}$ and $\mathrm{BX}, \mathrm{BC}: \mathrm{BX}$ ratio, and percent sucrose have been reported for table beet (Watson and Gabelman, 1984). Genetic correlations between pigment concentration and sugar content were small. BC and BX concentrations were correlated positively with each other and negatively with $\mathrm{BC}: \mathrm{BX}$ ratio.

The objectives of our study were to select high pigment-low solids (HPLS) and high pigment-high solids (HPHS) table beet populations and to determine the effect of selection on $\mathrm{BC}: \mathrm{BX}$ ratio. HPLS beets can be used as a source of pigment for food coloring, whereas HPHS beets would be desirable for the table beet processing industry.

\section{Materials and Methods}

\section{Selection procedure}

Population initiation. 1978-1980. Population initiation was begun by J.F. Watson in 1978. Open-pollinated red beet cultivars were screened for betalain pigment concentrations. Three U.S. cultivars (Garnet, Monoking Explorer, and Gladiator) and three European cultivars (Reglo, Rubia, and Boltardy) were chosen as parents for a high-pigment population. Roots were vernalized at $4 \mathrm{C}$ for 12 weeks, planted in the greenhouse, and the plants grown at $15 \mathrm{C}$ with $20 \mathrm{hr}$ of light daily. Inflorescences were shaken daily to disperse pollen. One-hundred-twenty plants, 20 from each of the six cultivars, were allowed to interpollinate. Gametophytic self-incompatibility facilitated outcrossing among plants. Equal quantities of seed from each plant were bulked and planted in a Kegonsa silt loam soil at Madison, Wis. At harvest, 150 roots were selected, and plants were induced to flower and interpollinated randomly. Seed was harvested separately from each of 105 plants, producing 105 half-sib families.

Cycle 0. On 1 July 1981, single rows of 105 half-sib families and four parental cultivars (Reglo, Boltardy, Rubia, and Garnet) were planted in rows $3.6 \mathrm{~m}$ long with $45 \mathrm{~cm}$ between rows. Sixty-nine days later, 10 roots ( 45 to $60 \mathrm{~mm}$ in diameter) from each row were harvested, washed, air-dried, and analyzed for pigment and dissolved solids concentrations. Family means for BC concentration and percent dissolved solids based on individual root analyses were calculated. Twenty families with the highest $\mathrm{BC}$ concentrations were selected. Within this group, the highest and lowest 10 families for percent dissolved solids were separated to form two new populations-HPHS and HPLS. Within the selected families, the seven best roots for BC content were selected, resulting in 70 roots (i.e., 10 families with seven roots per family for each population) for seed production. Seventy plants were open-pollinated and seed from each plant was harvested separately, producing 70 half-sib families in each of the HPHS and HPLS populations (C1).

Cycles 1, 2, and 3. C1, C2, and $\mathrm{C} 3$ populations, each grown in a different year, were planted and harvested, respectively, on 8 June and 10 Aug. 1982; 2 June and 8 Aug. 1983; 11 June and 14 Aug. 1984. For all cycles of the HPHS and HPLS populations, two replications of the 70 half-sib families and four parental cultivars were planted in the field as in 1981 .

Upon harvesting the $\mathrm{Cl}$ populations, 10 roots $(45$ to $60 \mathrm{~mm}$ diameter) in each family replication were kept for sampling. Individual root samples were analyzed for dissolved solids, but pigment analyses were completed on a bulked 5-g sample from each of 10 roots. Selection indices were used to identify the best families in each population. To select simultaneously for high pigment-high dissolved solids in the HPHS population, a selection index value was calculated as total pigment concentration $\times$ percent dissolved solids. Total pigment is the sum of $\mathrm{BC}$ and BX concentrations. In the HPLS population, the selection index value was calculated as total pigment concentration/ percent dissolved solids for the simultaneous selection of high pigment and low dissolved solids. In each population, the 10 families with the greatest calculated selection index values were chosen.

To minimize inbreeding, the pedigrees of the families were considered before selection. Each population consisted of 70 families, resulting from the open-pollination of 70 roots selected in the previous cycle. The 70 roots represented seven roots in each of 10 families. Thus, 70 families in each population were divided into 10 major families, each containing seven related subfamilies. By selecting the best one of seven subfamilies in each of 10 major families, inbreeding was minimized.

Individual root samples from selected families were analyzed for total pigment and within-family selection was practiced. Based on selection index values, seven roots consisting of the best three or four roots in each of the two replications were selected within each family. Selecting seven roots in each of the 10 families produced 70 half-sib families after interpollination within each of the HPLS and HPHS populations (C2). Continued selection in the $\mathrm{C} 2$, using the procedures described above, produced the $\mathrm{C} 3$ generation.

\section{Sampling and analysis for pigment and solids}

For pigment analysis, a tangential slice up to, but not including, the growing point was removed from each root and then diced into cubes of $<1 \mathrm{~cm}^{3}$. Another, smaller slice was taken for analysis of soluble solids concentration. Samples were stored frozen (-20C) until analysis.

Pigment analyses followed procedures of Watson and Gabelman (1982) with modifications. Frozen samples were placed in a Waring blender cup with a volume of water $(\mathrm{ml}) 1.5$ times the sample weight and homogenized at high speed for $5 \mathrm{~min}$. Additional water, twice the sample weight, was added and the samples homogenized further for $3 \mathrm{~min}$ at medium speed in a polytron homogenizer. Fifteen-milliliter aliquots of the samples were centrifuged for 40 min under refrigeration (4C) at 36,000x $g$. One milliliter of each supernatant was diluted to a volume of $100 \mathrm{ml}$, then analyzed spectrophotometrically following the procedures of Nilsson (1970). BC and BX values were expressed as $\mathrm{mg} / 100 \mathrm{~g}$ fresh weight for betanin and vulgaxanthine I, respectively.

Samples, sealed in polyethylene bags, were thawed to room temperature and pressed by hand to produce juice. One drop of juice was placed on the prism of a refractometer and percent dissolved solids was determined.

Pigment concentration is negatively correlated with root size in table beet (Nilsson, 1973; Watson and Gabelman, 1982). Sugar concentration is negatively correlated with root size in both table beet (Watson and Gabelman, 1982) and sugar beet (Powers, 1957). Since average root weights varied within the 45- to 60 -mm-size class, pigment and solids concentrations were adjusted based on covariance analysis before selection within each cycle.

\section{Realized heritability estimation}

Realized heritabilities for total pigment, solids, and selection index value were calculated by regressing the cumulative re- 
sponse on the cumulative selection differential for the $\mathrm{C} 1$ through C3 generation (Falconer, 1981).

\section{Statistical analysis}

Data were analyzed using the Statistical Analysis System (SAS). Since the cycles of selection were grown in different years, values for pigment and solids concentrations, $\mathrm{BC}: \mathrm{BX}$ ratio, and selection index were expressed as a percent of control (parental) cultivars. Values for a family in a given replication of a cycle were divided by the mean value of controls grown in that same replication. Since the $\mathrm{C} 0$ population was unreplicated and the $\mathrm{Cl}, \mathrm{C} 2$, and $\mathrm{C} 3$ generations were grown with two replications, the analysis of variance and multiple comparison test procedures were made only on the $\mathrm{Cl}, \mathrm{C} 2$, and $\mathrm{C} 3$ population data.

\section{Results}

Total pigment and solids concentrations for the control cultivars grown within the replicates of each population varied from cycle to cycle (year to year) (Tables 1 and 2). A significant year $\times$ control cultivar interaction was detected for total pigment concentration (data not shown). The means of the control cultivars for each of the four years of the experiment, however, were the best available determinants of environmental effects on the cycles that were grown in different years. Consequently, values for each cycle were expressed relative to the controls grown in the same year.

Cycles differed for relative total pigment concentrations and selection index values in both the HPHS and HPLS populations based on analyses of variance (ANOVA) (Tables 3 and 4). Error variance among cycles for total pigment was, however, 20 times larger in the HPLS than the HPHS population. Cycles did not differ in either population for relative values of solids or BC:BX ratio. Sub-families differed significantly for all traits in both populations.

Although the ANOVA detected differences among cycles for total pigment in the HPLS population, no differences among cycle means were found with the least significant difference multiple comparison test (Table 1). Selection index values of $\mathrm{C} 1, \mathrm{C} 2$, and $\mathrm{C} 3$ differed significantly for the least significant difference test, and values increased with each subsequent cycle of selection. In the HPHS population $\mathrm{Cl}, \mathrm{C} 2$, and $\mathrm{C} 3$ differed for both selection index value and total pigment, and the values increased with each subsequent cycle of selection (Table 2).

Since the C0 was grown unreplicated in the field, population means in the $\mathrm{C} 0$ population for the trait considered could not be compared statistically with cycles $\mathrm{C} 1-\mathrm{C} 3$. Relative total pigment and dissolved solids means appeared to increase from $\mathrm{C} 0$ to $\mathrm{C} 1$ for both populations. The increase in solids in the HPLS population was contrary to the selection for low dissolved solids in the $\mathrm{C} 0$ population.

Total pigment increased at rates of $18.4 \%( \pm 0.8 \%)$ and $22.2 \%$ $( \pm 0.8 \%)$ per cycle in the HPLS and HPHS populations, respectively. Relative solids increased at a rate of $3.0 \%( \pm 0.5 \%)$ per cycle in the HPHS population and decreased at a rate of $2.6 \%( \pm 0.5 \%)$ per cycle in the HPLS population. Both traits showed slightly greater rates of change in the HPHS population, probably accounting for the greater selection index value gain in that population. The selection index value increased at rates of $29.1 \%( \pm 1.2 \%)$ and $22.2 \%( \pm 0.9 \%)$ per cycle in the HPHS and HPLS populations, respectively.

Coefficients of variation for subfamily total pigment concentrations were $50 \%$ to $100 \%$ larger than values for solids in each cycle for both populations. Coefficients of variation for $\mathrm{BC}: \mathrm{BX}$ ratio were larger than those observed for either solids or total pigment (data not shown).

For the HPLS and HPHS populations, realized heritabilities were high for total pigment (0.81 and 0.82) and low for solids (0.25 and 0.27). Despite the low heritability for solids, realized heritability for selection index value was large in both populations (0.74 and 0.74).

\section{Discussion}

The use of simple selection indices in conjunction with halfsib family selection has led to improvement of the HPLS and HPHS populations. The multiplicative and divisional indices are simple and easy to use, unlike other indices, which use economic weights and estimate variances and covariances. Half-sib family selection was a simple but effective breeding method for red beet, a cross-pollinated, self-incompatible biennial. The

Table 1. Cycle means for total pigment concentration, percent dissolved solids, selection index, and betacyanin (BC) : betaxanthine (BX) ratio in the high pigment-low solids population.

\begin{tabular}{|c|c|c|c|c|c|c|}
\hline \multirow[b]{2}{*}{$\begin{array}{l}\text { Selection } \\
\text { cycle }\end{array}$} & \multicolumn{3}{|c|}{ Total pigment } & \multicolumn{3}{|c|}{ Solids } \\
\hline & $\begin{array}{l}\text { Controls }^{z} \\
(\mathrm{mg} / 100\end{array}$ & $\begin{array}{l}\text { Population } \\
\mathrm{g} \text { fresh } w t)\end{array}$ & $\begin{array}{l}\text { Relative }^{y, x} \\
\text { mean }\end{array}$ & $\begin{array}{c}\text { Controls } \\
(\%)\end{array}$ & $\begin{array}{c}\text { Population } \\
(\%)\end{array}$ & $\begin{array}{c}\text { Relative }^{y, x} \\
\text { mean }\end{array}$ \\
\hline $\mathrm{CO}$ & 175 & 167 & 95.3 & 7.9 & 8.0 & 101.7 \\
\hline $\mathrm{C} 1$ & 147 & 159 & $108.5 \mathrm{a}$ & 8.8 & 9.2 & $104.5 \mathrm{a}$ \\
\hline $\mathrm{C} 2$ & 144 & 181 & $125.5 \mathrm{a}$ & 9.2 & 9.3 & $101.0 \mathrm{a}$ \\
\hline \multirow[t]{3}{*}{$\mathrm{C} 3$} & 142 & 206 & $145.1 \mathrm{a}$ & 9.9 & 9.8 & $99.9 \mathrm{a}$ \\
\hline & \multicolumn{3}{|c|}{ Selection index } & \multicolumn{3}{|c|}{$\mathrm{BC}: \mathrm{BX}$ ratio } \\
\hline & \multicolumn{2}{|c|}{ (Pigment/solids) } & & & & \\
\hline $\mathrm{CO}$ & 22.7 & 21.2 & 93.5 & 2.51 & 2.31 & 92.1 \\
\hline $\mathrm{C} 1$ & 16.7 & 17.3 & $103.6 \mathrm{a}$ & 2.92 & 2.83 & $96.9 \mathrm{a}$ \\
\hline $\mathrm{C} 2$ & 15.7 & 19.5 & $124.2 \mathrm{~b}$ & 2.53 & 2.91 & $115.0 \mathrm{a}$ \\
\hline $\mathrm{C} 3$ & 14.3 & 21.0 & $147.0 \mathrm{c}$ & 2.72 & 2.92 & $107.4 \mathrm{a}$ \\
\hline
\end{tabular}

${ }^{z}$ Mean of four open-pollinated cultivars.

y Cycle mean when each family value is expressed as a percentage of control cultivars.

${ }^{{ }^{L S D_{0.05}}}$, different letters represent significant differences in each column among $\mathrm{C} 1$ through $\mathrm{C} 3$. 
Table 2. Cycle means for total pigment concentration, percent dissolved solids, selection index, and betacyanin $(\mathrm{BC})$ : betaxanthine $(\mathrm{BX})$ ratio in the high pigment-high solids population.

\begin{tabular}{|c|c|c|c|c|c|c|}
\hline \multirow[b]{2}{*}{$\begin{array}{l}\text { Selection } \\
\text { cycle }\end{array}$} & \multicolumn{3}{|c|}{ Total pigment } & \multicolumn{3}{|c|}{ Solids } \\
\hline & $\begin{array}{r}\text { Controls } \\
(\mathrm{mg} / 100\end{array}$ & $\begin{array}{l}\text { Population } \\
\mathrm{g} \text { fresh wt) }\end{array}$ & $\begin{array}{c}\text { Relative }^{\mathrm{y}, \mathrm{x}} \\
\text { mean }\end{array}$ & $\begin{array}{c}\text { Controls } \\
(\%)\end{array}$ & $\begin{array}{c}\text { Population } \\
(\%)\end{array}$ & $\begin{array}{c}\text { Relative } \\
\text { mean }\end{array}$ \\
\hline $\mathrm{CO}$ & 175 & 167 & 95.3 & 7.9 & 8.0 & 101.7 \\
\hline $\mathrm{C} 1$ & 154 & 158 & $102.4 \mathrm{a}$ & 8.6 & 9.7 & $112.7 \mathrm{a}$ \\
\hline $\mathrm{C} 2$ & 144 & 182 & $126.2 \mathrm{~b}$ & 9.2 & 10.9 & $118.5 \mathrm{a}$ \\
\hline \multirow[t]{3}{*}{$\mathrm{C} 3$} & 152 & 223 & $146.8 \mathrm{c}$ & 10.4 & 12.4 & $119.2 \mathrm{a}$ \\
\hline & \multicolumn{3}{|c|}{ Selection index } & \multicolumn{3}{|c|}{$\mathrm{BC}: \mathrm{BX}$ ratio } \\
\hline & (Pigment & $\times$ solids) & & & & \\
\hline $\mathrm{CO}$ & 1402 & 1353 & 96.5 & 2.51 & 2.31 & 92.1 \\
\hline $\mathrm{Cl}$ & 1326 & 1533 & $115.6 \mathrm{a}$ & 2.78 & 2.83 & $98.6 \mathrm{a}$ \\
\hline $\mathrm{C} 2$ & 1329 & 1987 & $149.5 \mathrm{~b}$ & 2.62 & 2.59 & $98.9 \mathrm{a}$ \\
\hline $\mathrm{C} 3$ & 1578 & 2761 & $175.0 \mathrm{c}$ & 3.00 & 2.97 & $99.0 \mathrm{a}$ \\
\hline
\end{tabular}

${ }^{2}$ Mean of four open-pollinated cultivars.

${ }^{y}$ Cycle mean when each family value is expressed as a percentage of control cultivars. ${ }^{\mathrm{x}} \mathrm{LS}_{0.05}$, different letters represent significant differences in each column among $\mathrm{C} 1$ through $\mathrm{C} 3$.

Table 3. Mean squares for relative total pigment concentration ${ }^{z}$, relative percent dissolved solids, relative selection index value, and relative betacyanin $(\mathrm{BC})$ : betaxanthine $(\mathrm{BX})$ ratio from the analysis of variance for cycles of selection (C1 through $\mathrm{C} 3$ ) in the high pigment-low solids population.

\begin{tabular}{|c|c|c|c|c|c|}
\hline Source & d.f. & $\begin{array}{c}\text { Total } \\
\text { pigment }\end{array}$ & $\begin{array}{l}\text { Percent } \\
\text { solids }\end{array}$ & $\begin{array}{c}\text { Selection } \\
\text { index }\end{array}$ & $\begin{array}{c}\mathrm{BC}: \mathrm{BX} \\
\text { ratio }\end{array}$ \\
\hline Cycle (C) & \multicolumn{2}{|c|}{$246,900.6^{*}$} & 1099.0 & $61,401.6^{*}$ & $11,570.3$ \\
\hline $\begin{array}{l}\text { Error }=\text { reps } \\
\quad(\mathrm{R}) / \mathrm{C}\end{array}$ & 3 & $3,536.4$ & 279.8 & $2,072.1$ & $2,446.0$ \\
\hline $\begin{array}{l}\text { Major families } \\
(\mathrm{F}) / \mathrm{C}\end{array}$ & 27 & 279.6 & 147.4 & 269.8 & 605.1 \\
\hline Error $=\mathrm{R} \times \mathrm{F} / \mathrm{C}$ & 27 & 181.8 & 98.7 & 221.6 & 327.8 \\
\hline $\begin{array}{l}\text { Subfamilies } \\
(\mathrm{S}) / \mathrm{F} / \mathrm{C}\end{array}$ & 179 & $228.9^{* *}$ & $65.6^{* *}$ & $231.7^{* *}$ & $354.0^{* *}$ \\
\hline Error $=$ & 178 & 93.5 & & & \\
\hline & $\begin{array}{l}176 \\
175 \\
178 \\
\end{array}$ & & 26.2 & 121.7 & 149.6 \\
\hline
\end{tabular}

${ }^{z}$ Values of sub-families expressed as a percentage of control cultivars.

**,* Significant at $P=0.01$ or 0.05 , respectively.

biennial nature of the beet permits selection among and within families before pollination. Interpollination of only selected plants, thereby controlling both the male and female components of the matings, doubles the expected gain per cycle compared to crops where uncontrolled pollination occurs prior to selection. Flowering in a greenhouse during the winter allows the completion of one selection cycle per year.

Three cycles of selection have increased relative selection index values in both red beet populations. Despite significant differences among cycles for relative total pigment concentration in both populations, as indicated by the ANOVA, the least significant difference multiple comparison test detected significant differences among cycle means only in the HPHS population and values increased with each subsequent cycle of selection. Since relative total pigment concentrations were sim -
Table 4. Mean squares for relative total pigment concentration ${ }^{2}$, relative percent dissolved solids, relative selection index value, and relative betacyanin $(\mathrm{BC})$ : betaxanthine $(\mathrm{BX})$ ratio from the analysis of variance for cycles of selection (C1 through $\mathrm{C} 3$ ) in the high pigment-high solids population.

\begin{tabular}{lccccc}
\hline Source & d.f. & $\begin{array}{c}\text { Total } \\
\text { pigment }\end{array}$ & $\begin{array}{c}\text { Percent } \\
\text { solids }\end{array}$ & $\begin{array}{c}\text { Selection } \\
\text { index }\end{array}$ & $\begin{array}{c}\text { BC:BX } \\
\text { ratio }\end{array}$ \\
\hline Cycle (C) & 2 & $69,120.0^{* *}$ & 1482.0 & $118,308.4^{* *}$ & 13.0 \\
$\begin{array}{l}\text { Error }=\text { reps } \\
\quad(\mathrm{R}) / \mathrm{C}\end{array}$ & 3 & 169.1 & 861.4 & $2,463.5$ & 6169.4 \\
$\begin{array}{l}\text { Major families } \\
\quad(\mathrm{F}) / \mathrm{C}\end{array}$ & 27 & $407.5^{* *}$ & 92.7 & $898.1^{* *}$ & $875.6^{*}$ \\
$\begin{array}{l}\text { Error }=\mathrm{R} \times \mathrm{F} / \mathrm{C} \\
\text { Subfamilies }\end{array}$ & 27 & 80.0 & 75.6 & 246.0 & 419.6 \\
$\quad(\mathrm{~S}) / \mathrm{F} / \mathrm{C}$ & 179 & $295.2^{* *}$ & $64.5^{* *}$ & $540.5^{* *}$ & $286.5^{* *}$ \\
& & & & &
\end{tabular}

Error $=$

$\mathrm{R} \times \mathrm{S} / \mathrm{F} / \mathrm{C}$

$178 \quad 93.7$

176
175
178

33.2

226.8 126.2

${ }^{2}$ Values of sub-families expressed as a percentage of control cultivars.

$* *$, Significant at $P=0.01$ or 0.05 , respectively.

ilar between the two populations for each cycle of selection, a greater error variance for the HPLS population most likely accounted for the nonsignificant least significant difference multiple comparison tests in that population. Although the cycles of selection did not differ for solids in both populations, the solids means did diverge, increasing and decreasing in the HPHS and HPLS populations, respectively. Continued selection is necessary to determine if the trends are leading to significant population improvement.

Selection did not affect BC:BX ratio in either population. The larger variation detected among families for this trait should allow future selection for specific $\mathrm{BC}: \mathrm{BX}$ ratios to meet the needs of the food industry.

The nonsignificant selection gains for solids of $3.0 \%$ and $-2.6 \%$ per cycle were only about one-sixth the rate of gain for 
total pigment observed in both populations: $18.4 \%$ and $22.2 \%$ per cycle. Heritability and genetic variation affect the rate of gain for the two traits. Both populations showed greater realized heritability and variation among families for total pigment than for solids, possibly explaining the different rates of gain. Realized heritability describes the response to selection, but may not be a true measure of heritability for several reasons (Falconer, 1981).

The high realized heritability for total pigment may be indicative of selection for a few major loci controlling pigment production. In this experiment, selection may have increased the frequency of one dominant allele of the multiple allelic series identified at the $R$ locus, which is associated with pigment concentration (Wolyn and Gabelman, 1989). If pigment concentrations are increasing rapidly due to selection for a specific $R$ allele, the rate of gain may plateau as the allele becomes fixed in the population.

The pigment levels of the two populations are presently 1.5 times that of the parental cultivars used to initiate the populations and twice that of cultivars currently used by the processing industry. Pigment extracts used for food coloring, containing twice the pigment levels of extracts from present-day cultivars, would be a contribution to the food industry because the volume of extract required to color food could be decreased by onehalf.

\section{Literature Cited}

Coons, G.H. 1936. Improvement of the sugar beet. Yearbook of agriculture. USDA, Washington, D.C. p. 625-656.
Falconer, D.S. 1981. Introduction to quantitative genetics. 2nd ed. Longman, New York.

Ng, T.J. and Y.N. Lee. 1978. Variation in betalain content among table beet cultivars. HortScience 13:581-582.

Nilsson, T. 1970. Studies into the pigments in beetroot. Lantbruhogsk. Annlr. 36:179-219.

Nilsson, T. 1973. The pigment content in beetroot with regard to cultivar, growth, development and growing conditions. Swedish J. Agr. Res. 3:187-200.

Pasch, J.H., J.H. von Elbe, and N. Dinesen. 1975. Betalain as natural food colorants. Food Prod. Dev. 9(9):38.

Powers, L. 1957. Identification of genetically superior individuals and the prediction of genetic gains in sugar beet breeding programs. J. Amer. Soc. Sugarbeet Technol. 9:408-432.

Riboh, M. 1977. Natural colors: what works... what doesn't. Food Engr. May. p. 66-72.

von E1be, J.H. 1978. The betalains, p. 29-39. In: T.E. Furia (ed.). Current aspects of food colorants. CRC Press, Cleveland, Ohio.

von Elbe, J.H., I.Y. Maing, and C.H. Amundson. 1974. Color stability of betanin. J. Food Sci. 39:334-337.

von Elbe, J.H., S.H. Sy, I.L. Maing, and W.H. Gabelman. 1972. Quantitative analysis of betacyanins in red table beet (Beta vulgaris). J. Food Sci. 37:932-934.

Watson, J.F. and W.H. Gabelman. 1982. Seasonal changes and cultivar differences in pigment concentrations and percent dissolved solids in roots of table beet. J. Amer. Soc. Hort. Sci. 107:713-716.

Watson, J.F. and W.H. Gabelman. 1984. Genetic analysis of betacyanine, betaxanthine, and sucrose concentrations in roots of table beet. J. Amer. Soc. Hort. Sci. 109:386-391.

Wolyn, D.J. and W.H. Gabelman. 1989. Inheritance of root and petiole pigmentation in red table beet. J. Hered. 80:33-38. 